\title{
ESTABILIDADE OPERACIONAL DA ENZIMA COMERCIAL Candida antarctica B (CAL B) IMOBILIZADA EM MATRIZ HIDROFÓBICA
}

\author{
A. M. M. FICANHA ${ }^{1}$, I. A. FERNANDES ${ }^{1}$, N. L. D. NYARY ${ }^{1}$, K. LEVANDOSKI ${ }^{1}$, R. \\ DALLAGO $^{1}$, M. MIGNINI $^{1}$ \\ ${ }^{1}$ Universidade Regional Integrada do Alto Uruguai e Missões, URI- Erechim, RS, Departamento \\ de Engenharia de Alimentos \\ E-mail para contato: alinematuella@gmail.com
}

\begin{abstract}
RESUMO - Enzimas são biocatalisadores com ampla aplicação em diversos tipos de reações, porém, o custo elevado das enzimas solúveis é um dos limitadores de sua aplicação, pois são descartadas após a reação e seu uso se torna economicamente inviável. O objetivo deste trabalho foi testar a estabilidade operacional da enzima lipase de Candida antarctica B (CAL B) imobiliza em matriz hidrofóbica obtida pela técnica sol-gel. A metodologia de imobilização foi adaptada de Soares et al (2006) utilizando polietilenoglicol como aditivo e meio ácido, básico e nucleofílico como catalisadores para a formação do sol-gel. Devido à falta de uma metodologia definida na literatura, a estabilidade operacional do reuso foi realizada de 3 formas (modo direto, com lavagem e reuso a cada 24 horas). Os resultados demonstram a possibilidade de reuso dos derivados, sendo que o número maior de ciclos foi de sete reusos, até a enzima chegar em uma atividade residual de $50 \%$. Além disto, foi possível observar o efeito do tipo de tratamento entre os ciclos, a lavagem com hexano, por exemplo, proporcionou o menor número de reciclos (3). A imobilização conferiu uma maior estabilidade operacional no que diz respeito ao seu uso e reuso na reação de síntese de oleato de etila.
\end{abstract}

\section{INTRODUÇÃO}

O mercado mundial de enzimas apresenta perspectiva no faturamento para 2014 de US\$ 4 bilhões. Porém, o maior desafio nas últimas décadas foi contornar a problemática do uso de enzimas na forma livre, que não podem ser reutilizadas por serem solúveis nos meios reacionais. Neste sentido, o uso de técnicas que possibilitem à estabilidade é desejável na produção de biocatalisadores para aplicações industriais (Bon et al., 2008).

Diversas técnicas têm sido desenvolvidas com a finalidade de minimizar estes inconvenientes, como por exemplo, a imobilização de enzimas, que possibilita a reutilização do biocatalisador e minimiza o custo de separação dos produtos, com isso, o inconveniente econômico associado ao seu uso. A imobilização também fornece flexibilidade operacional e melhora a estabilidade térmica e química das enzimas (Balcão et al., 1996; Sabbani et al., 2006; Wang e Hsieh, 2008). 


\section{9 a 22 de outubro de 2014 \\ Florianópolis/SC}

O encapsulamento pela técnica de sol-gel tem provado ser uma forma particularmente fácil e eficaz para imobilizar enzimas e os derivados de lipase de sol-gel mostram-se excelentes catalisadores, podendo ser utilizados em batelada sem qualquer perda da atividade catalítica (Yilmaz et al., 2011).

O objetivo deste trabalho foi testar o reuso da enzima lipase comercial de Candida antarctica B imobilizada em matriz hidrofóbica, obtida pela técnica sol-gel, na síntese de oleato de etila

\section{METODOLOGIA}

\subsection{Imobilização}

A lipase de Candida antarctica B foi imobilizada por encapsulamento em uma matriz hidrofóbica obtida pela técnica sol-gel. A metodologia empregada foi adaptada da descrita por Soares et al. (2006). Inicialmente, $5 \mathrm{~mL}$ de TEOS foram dissolvidos em $5 \mathrm{~mL}$ de etanol absoluto. Após a dissolução, adicionou-se 1,6 mL de água destilada e três gotas do catalisador. Posteriormente, os sistemas reacionais foram submetidos a uma etapa de agitação, em agitador orbital (shaker), a $40{ }^{\circ} \mathrm{C}$, $180 \mathrm{rpm}$, por um período de 90 minutos. Passado este período, fez-se a adição de $1 \mathrm{~mL}$ da solução enzimática na concentração de $160 \mathrm{mg} \cdot \mathrm{mL}^{-1}$. Nas amostras para o teste do uso do aditivo, foram adicionados $1 \mathrm{~mL}$ de uma solução do aditivo PEG $1500\left(5 \mathrm{mg} \cdot \mathrm{mL}^{-1}\right)$. As amostras foram mantidas em condições estáticas por 48 horas para completar a condensação química e a secagem.

\subsection{Síntese de oleato de etila}

A atividade de esterificação foi quantificada através da reação de síntese de oleato de etila utilizando ácido oleico e álcool etílico na razão molar de 1:1 (mistura padrão), conforme descrito por Ferraz et al. (2012). A reação foi iniciada pela adição de $0,1 \mathrm{~g}$ de enzima imobilizada em 5 $\mathrm{mL}$ da mistura padrão. A reação foi conduzida a $40{ }^{\circ} \mathrm{C}, 160 \mathrm{rpm}$, por 40 minutos. Alíquotas de $500 \mu \mathrm{L}$ foram retiradas do meio reacional em triplicata. A cada amostra foram adicionados 15 $\mathrm{mL}$ de uma solução de acetona-etanol (1:1) (v/v) para paralisar a reação. A quantidade de ácido oleico consumido foi determinado por titulação com $\mathrm{NaOH} 0,05$ mol. $\mathrm{L}^{-1}$ até o meio atingir $\mathrm{pH}$ 11.

\subsection{Estabilidade operacional}

A estabilidade operacional foi realizada de 3 formas distintas (i, ii, iii). Estes procedimentos foram realizados no final de cada ciclo de reação, no qual, o produto (fase líquida) foi removido com uma pipeta e foi mantido a fase sólida (derivado imobilizado). As reações foram repetidas até o derivado chegar a uma atividade de esterificação residual maior ou igual a $50 \%$ da atividade inicial.

i) direto: após os 40 minutos de reação, o meio reacional foi removido do sistema, fez-se nova adição da solução padrão (ácido oleico e etanol), levou-se a amostra para nova reação.

ii) com lavagem: após a remoção do meio reacional, o derivado imobilizado foi submetido a 
uma etapa de lavagem com hexano ( 2 vezes com $2 \mathrm{~mL}$ de hexano). Após, o meio foi centrifugado a 5000 rpm. Retirou-se o hexano sobrenadante, deixou-se o derivado em estufa a $40{ }^{\circ} \mathrm{C}$ por aproximadamente 1 hora para a evaporação do solvente residual. Posteriormente, as mesmas quantidades de solução padrão foram adicionadas ao derivado para a próxima reação;

iii) reuso a cada 24 horas: as reações foram conduzidas a cada 24 horas, mantendo o imobilizado armazenado em geladeira. No inicio de cada ciclo fez-se a substituição do meio pela mistura reacional padrão.

\section{RESULTADOS E DISCUSSÕES}

A reutilização de enzimas em mais de um ciclo de reação é um dos principais objetivos da imobilização, este fato é importante para as enzimas lipase devido ao seu preço, visto que, o custo da enzima é um dos principais problema quando se refere a sua aplicação industrial.

Considerou-se para o reciclo, atividade residual maior ou igual a $50 \%$ do valor da atividade inicial. A possibilidade de reutilizar a lipase de Candida antarctica B imobilizada foi determinada por reações de síntese de oleato de etila, apresentados nas Figuras 1, 2 e 3 respectivamente.

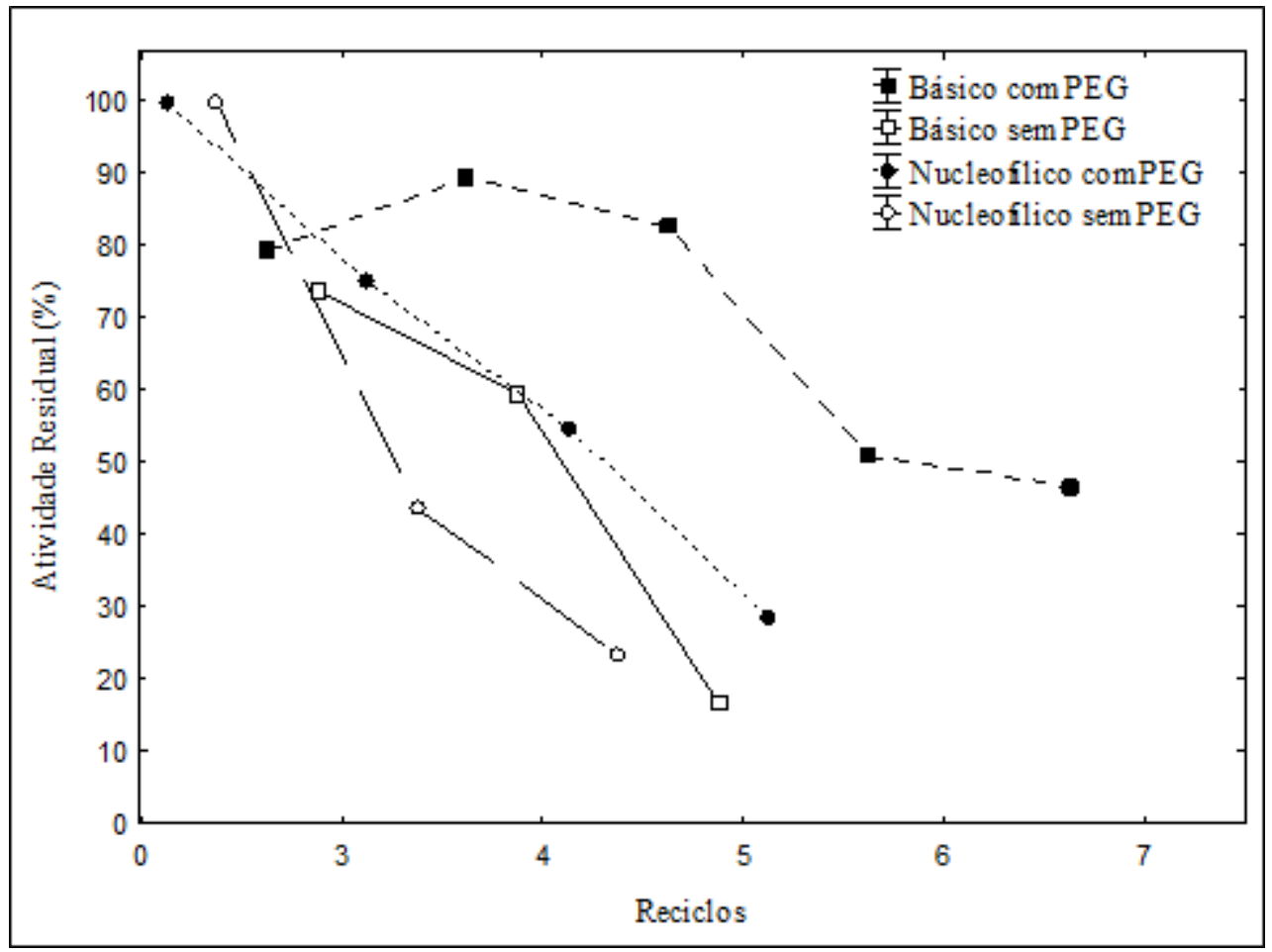

Figura 1 - Atividade residual do reuso direto. 


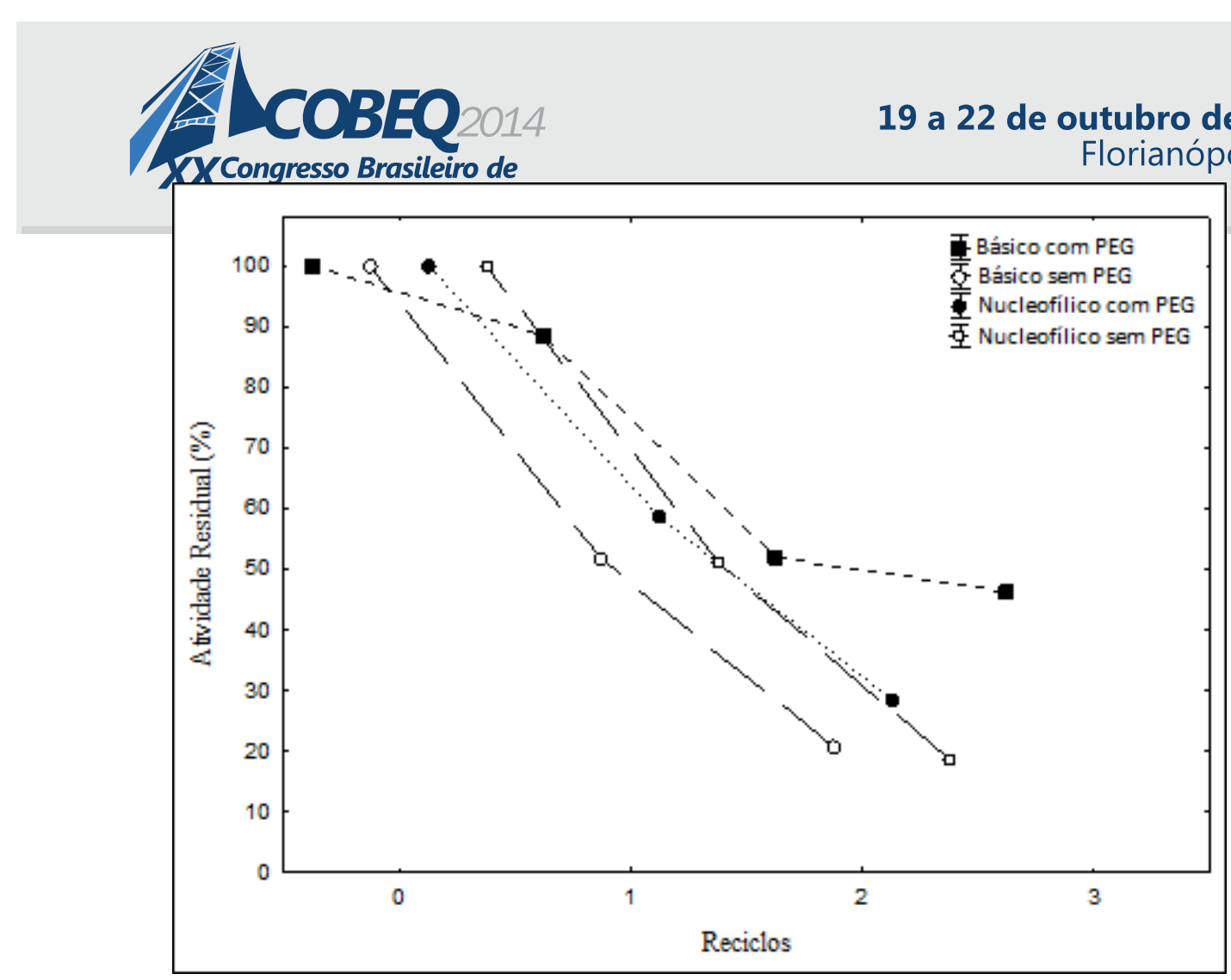

Figura 2 - Atividade residual do reuso com lavagem.

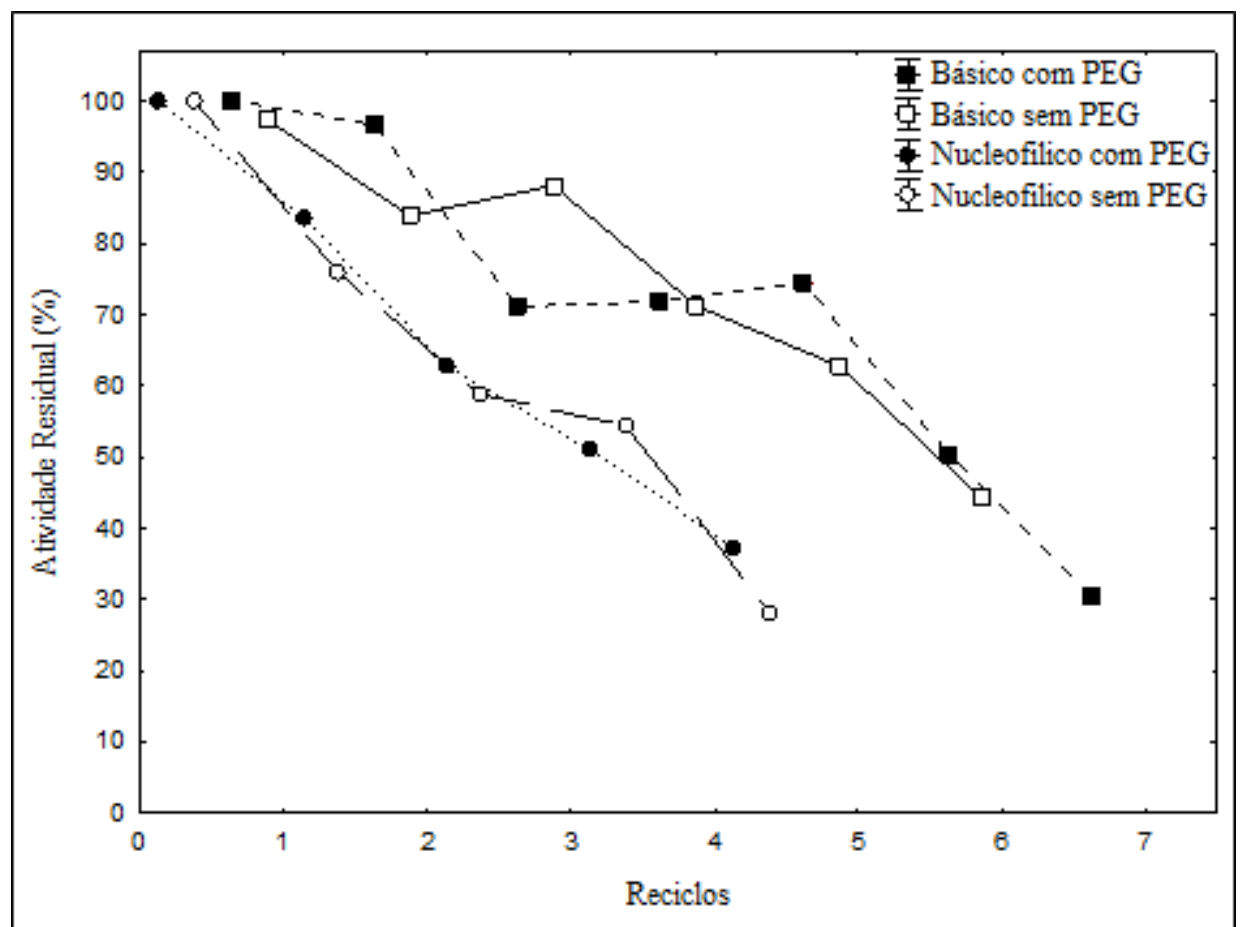

Figura 3 - Atividade residual do reuso a cada 24horas.

De acordo com a Figura 1, para o método contínuo, os derivados com PEG apresentaram melhores resultados do que os sintetizados na ausência do PEG, sendo que o derivado básico com 5 reusos foi o que apresentou os melhores resultados. Os resultados referentes ao reuso contínuo lavado com hexano (Figura 2) apresentam similaridade de tendência e valores, aos observados para o reuso 
contínuo. O único derivado a apresentar mais de um reuso (com 3 reusos) foi o básico com PEG.

Para o reuso a cada 24 h (Figura 3) o derivado básico apresentou um número maior de reciclos do que o derivado nucleofílico.

Independentemente do tipo de reuso o maior número de repetições foi observado para o suporte básico com PEG. Dentre os reusos, o método com maior reusos foi o direto. Os resultados obtidos evidenciam o efeito estabilizante do aditivo PEG, o qual atribui o aumento da estabilidade, devido a provável proteção da enzima contra a desnaturação da enzima (Carvalho, 2011; Soares et al., 2006).

Cabe ressaltar que o decréscimo da atividade na catálise com consequência da redução da atividade residual pode estar relacionada à perda do suporte durante o processo, uma vez que o mesmo apresenta-se na forma de pó finamente dividido, o que dificulta sua recuperação para o reuso seguinte. Este fato pode justificar o menor número de reusos observados para o ensaio conduzido com lavagem de hexano.

Diversos trabalhos de pesquisa focada em melhorar a estabilidade e a reutilização de enzimas imobilizadas, possibilitaram a sua aplicação em escala industrial. Hara et al. (2008) mostrou que a lipase Amano PS de Burkholderia cepacia imobilizada por aprisionamento em sol-gel, com 8 reusos, apresentou uma boa capacidade de reutilização à temperatura ambiente. Resultados semelhantes foram obtidos por Yilmaz et al. (2011 e 2010) para a lipase de Candida rugosa, a qual permitiu sua reutilização por 5 vezes a $30{ }^{\circ} \mathrm{C}$. Souza et al. (2012) conseguiu 3 reusos para a lipase de Bacillus sp. imobilizada pela técnica sol-gel utilizando Aliquat 336 como aditivo. Carvalho (2013) e Simões et al. (2011), descreveram que a estabilidade operacional da atividade de esterificação foi menor que $50 \%$ da atividade inicial após o segundo uso da lipase de Bacillus sp. ITP-001 imobilizada em matrizes hidrofóbicas pela técnica sol-gel.

\section{CONCLUSÃO}

De acordo com os resultados, o uso da enzima comercial de Candida antarctica B (CAL B) imobilizada, possibilitou a reutilização da enzima e demonstrou potencial de sua aplicação em reação de esterificação, fornecendo informações importantes em relação à utilização da enzima no processo industrial.

\section{REFERÊNCIAS}

BALCÃO, V. M.; PAIVA, A. L.; MALCATA, F. X. Bioreactors with immobilized lipases: State of the art. Enzyme Microb. Technol., v. 18, p. 392-416, 1996.

BON, E. P. S.; MARIA, A.; FERRERA, M. A.; CORVO, M. L.; VERMELHO, A. B.; PAIVA, C. L. A.; ALENCASTRO, R. B.; COELHO, R. R. R. Enzimas em Biotecnologia: Produção, Aplicação e Mercado. Editora Interciência, Rio de Janeiro, 2008. 
CARVALHO, N. B.; BARBOSA, J. M. P.; OLIVEIRA, M. V. S.; FRICKS, A. T.; LIMA A. S.; SOARES, C. M. F. Biochemical properties of Bacillus sp. ITP-001 lipase immobilized with a sol-gel process. Quim. Nova., v. 36, n. 1, p. 52-58, 2013.

FERRAZ, L. R; OLIVEIRA, D. S.; SILVA, M. F.; RIGO, E.; DI LUCCIO, M.; OLIVEIRA, J. V.; OLIVEIRA, D.; TREICHEL, H. Production and partial characterization of multifunctional lipases by Sporobolomyces ruberrimus using soybean meal, rice meal and sugarcane bagasse as substrates. Biocatal. Agric. Biotechnol., v. 1, p. 243-252, 2012.

HARA, P.; HANEFELD, U.; KANERVA, L.T. Sol-gels and cross-linked aggregates of lipase PS from Burkholderia cepacia and their application in dry organic solvents. J. Mol. Catal. B: Enzym., v. 50, p. 80-86, 2008.

SABBANI, S.; HEDENSTRÖM, E.; NORDIN, O. The enantioselectivity of Candida rugosa lipase is influenced by the particle size of the immobilising support material Accurel. J. Mol. Catal. B: Enzym., v. 42, p. 1-9, 2006.

SIMÕES, A. S.; MORI, R. Y.; FARIA, R.; CASTRO, H. F. MENDES, A. A. Desempenho da matriz híbrida $\mathrm{SiO}_{2}$-quitosana na imobilização da lipase microbiana de Candida rugosa. Quim. Nova., v. 34, p. 33-38, 2011

SOARES, C. M. F.; SANTOS, O. A.; CASTRO, H. F.; MORAES, F. F.; ZANIN, G. M. Characterization of sol-gel encapsulated lipase using tetraethoxysilane as precursor. J. Mol. Catal. B: Enzym., v. 39, p. 69-76, 2006.

SOUZA, R. L.; RESENDE, W. C.; BARÃO, C. E.; ZANIN, G. M.; CASTRO, H. F. DE; SANTOS, O. A. A.; FRICKS, A. T.; FIGUEIREDO, R. T.; LIMA, A. S.; SOARES, C. M. F. Influence of the use of Aliquat 336 in the immobilization procedure in sol-gel of lipase from Bacillus sp. ITP-001. J. Mol. Catal. B. Enzym., v. 84, p.152-159, 2012.

WANG, Y.; HSIEH, Y. L. Immobilization of lipase enzyme in polyvinyl alcohol (PVA) nanofibrous membranes. J. Membr. Sci., v. 309, p. 73-81, 2008.

YILMAZ, E.; SEZGIN, M.; YILMAZ, M. Enantioselective hydrolysis of rasemic naproxen methyl ester with sol-gel encapsulated lipase in the presence of sporopollenin. J. Mol. Catal. B: Enzym,. v. 62, p. 162-168, 2010.

YILMAZ, E.; SEZGIN, M.; YILMAZ, M. Immobilization of Candida rugosa lipase on magnetic sol-gel composite supports for enzymatic resolution of (R,S)-Naproxen methyl ester. J. Mol. Catal. B: Enzym., v. 69, p. 35-41, 2011. 